\title{
Administration of vascular endothelial growth factor Trap during the 'post-angiogenic' period of the luteal phase causes rapid functional luteolysis and selective endothelial cell death in the marmoset
}

\author{
Hamish M Fraser, Helen Wilson, Christine Wulff ${ }^{1}$, John S Rudge ${ }^{2}$ and Stanley J Wiegand ${ }^{2}$ \\ Medical Research Council Human Reproductive Sciences Unit, The Queen's Medical Research Institute, 47 Little \\ France Crescent, Edinburgh EH16 4TJ, UK, ${ }^{1}$ Department of Obstetrics and Gynaecology, University of Ulm, Ulm, \\ Germany and ${ }^{2}$ Regeneron Pharmaceuticals, Tarrytown, New York 10591, USA
}

Correspondence should be addressed to H M Fraser; Email: h.fraser@hrsu.mrc.ac.uk

\begin{abstract}
The intense angiogenesis characteristic of early corpus luteum development is dependent upon vascular endothelial growth factor (VEGF) as inhibitors of VEGF administered at the peri-ovulatory period suppress endothelial cell proliferation and progesterone secretion. We now report that administration of VEGF Trap, a soluble decoy receptor-based inhibitor, at the mid- or the late luteal phase in the marmoset results in a rapid decline in plasma progesterone. Since vascularisation of the corpus luteum is largely complete by the mid-luteal phase, it suggested that this functional luteolysis involved mechanisms other than inhibition of angiogenesis. A second experiment investigated the role of VEGF in maintaining the integrity of the luteal vasculature and hormone-producing cells. VEGF Trap was administered to marmosets in the mid-luteal phase and ovaries were obtained 1, 2, 4 or 8 days later for localisation of activated caspase- 3 staining in the corpus luteum and compared with those obtained 2, 4 and 8 days after administration of control protein. The number of cells with activated caspase-3 staining was significantly increased after administration of VEGF Trap. Dual staining of activated caspase-3 with the endothelial cell marker CD31 showed that at 1 day post-treatment, more than $90 \%$ caspase-3-stained cells were vascular endothelium, prior to detection of an increasing incidence in death of hormone-producing cells on days 2 and 4. Staining with CD31 showed that the endothelial cell area was decreased after treatment. By 8 days after treatment, corpora lutea had regressed to varying degrees, while all control corpora lutea remained healthy. These results show that VEGF inhibition in the mid- or the late luteal phase induces functional luteolysis in the marmoset that is associated with premature and selective death of endothelial cells.
\end{abstract}

Reproduction (2006) 132 589-600

\section{Introduction}

The early luteal phase is associated with intense angiogenesis that is necessary for normal functioning of the corpus luteum to produce the progesterone essential for the establishment of pregnancy. Several factors regulating the angiogenic pathway have been identified and a number of specific antagonists have been developed, which are being employed for clinical application in the treatment of solid tumours (Jain et al. 2006). Since a proportion of these patients will be pre-menopausal women, it is crucial that their potential effects on the reproductive system be elucidated fully using non-human primate models. At the same time, these antagonists provide us with tools by which their role of specific factors in the remarkable phenomenon of cyclical angiogenesis, which occurs in the corpus luteum, may be used as a model to further elucidate the molecular regulation of physiological angiogenesis (Fraser \& Duncan 2005). We have undertaken a series of studies in which one of the principal angiogenic and vascular permeability factors, vascular endothelial growth factor (VEGF), has been inhibited in vivo at selected stages of the ovulatory cycle using the marmoset monkey as a model. For example, the cellular and the molecular changes associated with the inhibition of VEGF during the early luteal phase using either a MAB (Fraser et al. 2000) or a VEGF-R1 Trap, have been studied in detail and demonstrated that treatment results in inhibition of endothelial cell 
proliferation, restriction in development of the luteal microvascular tree and suppression of luteal function, as monitored by plasma progesterone concentrations (Wulff et al. 2001b). Relatively little is known about the effects of inhibition of VEGF during the mid- and the late luteal phases. Although angiogenesis is largely complete by this time (Dickson \& Fraser 2000), the functioning of the corpus luteum is essential for implantation and maintenance of early pregnancy (Jabbour et al. 2006). It is also known that synthesis of VEGF continues during the mid-luteal phase in the marmoset (Rowe et al. 2002) as in the human corpus luteum (Wulff et al. 2001a). It is therefore important that any non-angiogenic role for VEGF at this time be elucidated. These may include maintenance of the new blood vessels or the enhancement of vascular permeability.

In the present study, a receptor-based VEGF inhibitor, the VEGF Trap, was administered at the mid- or the late luteal phase to determine whether VEGF inhibition might also affect luteal function, when treatment initiated after vascularisation of the corpus luteum is largely complete. Surprisingly, these studies revealed that inhibition of VEGF in the mid- or the late luteal phase produced a rapid, marked and sustained suppression of plasma progesterone levels. To determine if the VEGF Trap had an effect on the luteal vasculature and the integrity of the hormone-producing cells, a second study was conducted. Marmosets were again treated with VEGF Trap at the mid-luteal phase and ovaries collected 1, 2, 4 or 8 days later. The effects of treatment on the incidence of cell death were determined by localisation and quantification of activated caspase-3. The appearance of activated caspase-3 is an early and sensitive indicator of cell death, typically being evident before classical morphological changes indicative of apoptosis are apparent. Luteal regression is associated with an increase in the numbers of cells immunoreactive for activated caspase3 in all species studied to date, including macaques (Peluffo et al. 2005) and caspase-3 activation appears to be essential for normal luteolysis based on studies of knockout mice (Carambula et al. 2002). In addition, dual staining for activated caspase-3 and the endothelial cell marker CD31 was used to monitor the identity of the dying cells, to test the hypothesis that inhibition of VEGF would lead to a selective death of the recently formed endothelium in the corpus luteum. Animals studied 1, 2 and 4 days after treatment permitted the identification of cells in the corpus luteum susceptible to deprivation of VEGF, while those examined after 8 days allowed us to determine whether the treatment resulted in premature structural luteolysis since copora lutea of the 20-day luteal phase in control marmosets are still functionally and structurally intact at this stage.

\section{Material and Methods}

\section{Animals and treatments}

The study was approved by the local Primate Ethical Committee and carried out under Project Licences PPL 60/2472 and PPL 60/3250 granted by the UK Home Office. Adult female marmosets (Callithrix jacchus), weighing between 330 and $430 \mathrm{~g}$ were housed in cages with a younger sister or prepubertal female. Under these conditions, the older dominant marmoset exhibits ovulatory cycles. Ovulation was determined by measuring plasma progesterone profiles on samples collected on Monday, Wednesday and Friday. Plasma progesterone levels are $<32 \mathrm{nmol} / \mathrm{l}$ during the follicular phase in the marmoset. Ovulation was designated luteal day 0 and defined as the day preceding a rise in progesterone concentration above $32 \mathrm{nmol} / \mathrm{l}$ followed by a progressive increase in progesterone. These criteria have been established in other marmoset colonies (Harlow et al. 1983, 1984, Gilchrist et al. 2001). By measuring progesterone in blood samples according to the above definition, the day of ovulation could be identified within \pm 1 day. In normal cycles, progesterone continues to rise and remains elevated for approximately 20 days before falling to follicular phase levels once again (Harlow et al. 1983, 1984). Marmosets exhibiting at least one ovulatory cycle immediately prior to being recruited into the study were selected. In the first study, to determine the acute effects of VEGF inhibition on luteal function and assess the time taken to return to normal cycles, marmosets ( $n=5$ per group) were treated with a single dose of VEGF TrapR1R2 (25 mg/kg s.c.) on days 8-10, mid-luteal or days 13-15, post-ovulation (late luteal phase). The VEGF Trap, a potent inhibitor of VEGF, is a recombinant protein comprising ligand-binding domains of human VEGF-R1 and VEGF-R2, expressed in sequence with the constant region $(\mathrm{Fc})$ domain of human immunoglobulin (Holash et al. 2002). Control marmosets were injected with recombinant human Fc $(25 \mathrm{mg} / \mathrm{kg}$ s.c.) at the late luteal phase.

To determine the pharmacokinetics of VEGF Trap in the systemic circulation following s.c. injection, blood samples were obtained from the group treated at the mid-luteal phase at 1,4 and $8 \mathrm{~h}$, and on 1, 2, 4, 7, 9, 11, 16 and 18 days post-injection in both groups for the determination of plasma concentrations of VEGF Trap. Blood samples continued to be collected for determination of plasma progesterone levels until the end of the first post-treatment ovulatory cycle.

A second experiment was designed to determine the effects of VEGF inhibition on the corpus luteum at the morphological level with specific reference to the localisation and changes in activated caspase-3. Marmosets were treated with a single injection of $25 \mathrm{mg} / \mathrm{kg}$ s.c. VEGF Trap, as above, at the mid-luteal phase. Ovaries were collected 1, 2, 4 ( $n=4$ per group) and $8(n=6)$ days later. Control animals received 
$25 \mathrm{mg} / \mathrm{kg}$ s.c. Fc at the mid-luteal phase and were studied 2,4 and 8 days later ( $n=4$ per group). Thus, the day 2 Fc animals served as controls for the days 1 and 2 VEGF Trap-treated groups.

After injection of VEGF Trap or Fc, blood samples were collected on day one post-treatment and every 1 or 2 days thereafter. On days 1, 2, 4, or 8 post-treatment, animals were injected i.v. with $20 \mathrm{mg}$ bromodeoxyuridine (BrdU; Boehringer-Mannheim, Essex, UK) in saline $1 \mathrm{~h}$ before being sedated using $100 \mu \mathrm{l}$ ketamine hydrochloride (Parke-Davis Veterinary, Pontypool, Gwent, UK) and killed with an i.v. injection of $400 \mu \mathrm{l}$ Euthetal (sodium pentobarbitone, Rhone Merieux, Harlow, Essex, UK). After cardiac exsanguination, the ovaries were removed immediately. The corpora lutea of the cycle were identified macroscopically and the ovaries bisected along the line of maximal luteal area, prior to fixation in 4\% neutral-buffered formalin (Van Waters \& Rogers International Ltd, Leicestershire, UK). Other tissues were collected for studies to be described elsewhere. After $24 \mathrm{~h}$, the ovaries were transferred into $70 \%$ ethanol, dehydrated and embedded in paraffin according to standard procedures.

\section{Assays}

Plasma concentrations of progesterone and VEGF Trap were measured as described previously (Wulff et al. $2001 b$, Fraser et al. 2005a,b), Samples for VEGF Trap assay were diluted 1:10 000 .

\section{Haematoxylin-eosin staining}

To determine effects on luteal area and morphology, tissue sections $(5 \mu \mathrm{m})$ were placed on SuperFrost slides (Merck). These sections were dewaxed in xylene, rehydrated in descending concentrations of ethanol, washed in distilled water and stained with haematoxylin (Richard-Allan, Richland, MI, USA) for 5 min, followed by a wash in water and acetic alcohol before staining with eosin (Richard-Allan) for $20 \mathrm{~s}$. After dehydrating in ascending concentrations of ethanol and xylene, they were mounted.

\section{Immunocytochemistry}

For immunocytochemistry, antigen retrieval was performed by pressure-cooking (Tefal Clypso pressure cooker, Tefal, Essex, UK) sections to boiling point, in $0.01 \mathrm{M}$ citrate buffer ( $\mathrm{pH} \mathrm{6)}$, for $5 \mathrm{~min}$. The sections were left for $20 \mathrm{~min}$ in the hot buffer and washed in Tris buffered saline (TBS) $(0.05 \mathrm{~mol} / / \mathrm{l}$ Tris and $9 \mathrm{~g} / \mathrm{l} \mathrm{NaCl})$. To determine the localisation and changes in the number of dying cells, a rabbit antibody to activated caspase-3 (Asp175; New England Biolabs, Hitchen, UK) was used. After pressure-cooking, endogenous peroxidase activity was quenched by 5 -min incubation in peroxidase block (EnVision HRP kit, Dako, Cambridgeshire, UK) at room temperature, after which the slides were washed and blocked with normal goat serum (NGS, diluted 1:5 in TBS containing $5 \%$ BSA for $30 \mathrm{~min}$ at room temperature). The sections were then incubated overnight at $4{ }^{\circ} \mathrm{C}$ with activated caspase- 3 antibody at 1:100 dilution in NGS. Slides were then washed in TBS and incubated with labelled polymer-HRP as secondary antibody (rabbit EnVison kit) for $30 \mathrm{~min}$. Visualisation was achieved by 3-3'-diaminobenzidine (DAB) Substrate (EnVison kit); sections were then counterstained with haematoxylin, dehydrated and mounted in Pertex.

Dual staining for CD31 (platelet endothelial cell adhesion molecule) and activated caspase- 3 utilised the antigen retrieval system with peroxidase and goat serum block as earlier, followed by avidin/biotin blocking (Vector Kit, Vector Laboratories Inc., Peterborough, UK) according to kit instructions. Primary antibody against CD31 (mouse anti-human CD31, Dako) was diluted 1:20 in NGS and incubated overnight at $4{ }^{\circ} \mathrm{C}$. Slides were incubated with a biotinylated goat anti-mouse secondary antibody (Dako) at diluted 1:500 in NGS, for 30 min, washed and incubated with avidin-biotin-alkaline-phospahate complex (ABC-AP, Dako), for $30 \mathrm{~min}$ at room temperature, and visualised with Fast Blue (Sigma). They were washed well in water followed by TBS, blocked again with NGS and stained for caspase-3 as described earlier. No counter-stain was used. They were air-dried, put in xylene and mounted in Pertex.

The effects of the treatment on endothelial cell proliferation and vascular density were determined by quantifying the number of proliferating cells stained for BrdU and by localising endothelial cells using CD31. Tissue sections were blocked with normal rabbit serum and then placed in TBS containing primary antibodies to CD31 or BrdU (mouse anti-BrdU; Roche Molecular Biochemicals) diluted $1: 20$ or $1: 30$ respectively. Incubation was carried out overnight at $4{ }^{\circ} \mathrm{C}$. Slides were washed in TBS, incubated with the secondary antibody, rabbit antimouse Ig (diluted 1:60 in normal rabbit serum TBS; Dako), for $40 \mathrm{~min}$ at room temperature, and again washed in TBS and incubated with alkaline phosphatase-anti-alkaline phosphatase (APAAP) complex (diluted 1:100 in TBS; Dako), for 40 min at room temperature. Visualisation was performed using nitro blue tetrazolium (NBT) solution containing $45 \mu \mathrm{l} \mathrm{NBT}$ substrate (Roche Molecular Biochemicals), $10 \mathrm{ml}$ NBT buffer, $35 \mu \mathrm{l}$ 5-bromo-3-chloro-3indolyl-phosphate and $10 \mu \mathrm{l}$ levamisole. Sections for BrdU were counterstained with haematoxylin, whereas those for CD31 were not counterstained, so that quantitative image analysis could be performed.

\section{Quantitative image analysis}

Quantitative image analyses of luteal area, cell proliferation and vascular density measurements, were 
performed using an Olympus $\mathrm{BH} 2$ microscope, Spot Insight QE camera and Image-Pro Plus version 4.5 for Windows (Media Cybernetics, Silver Spring, MD, USA). Captured images were thresholded and ten areas per corpus luteum were outlined from randomly selected fields. All corpora lutea were analysed under $40 \times$ magnification for all parameters. Since all animals had ovulated two to four corpora lutea, single values for individual animals were calculated by taking the mean of the measurements obtained for all the corpora lutea in that animal.

Luteal circumference was measured in sections of the ovary cut through the centre of the largest corpus luteum and the maximal cross-sectional area of each corpus luteum was calculated using Image ProPlus.

Changes in lutein cell area were determined in haematoxylin- and eosin-stained sections under a $40 \times$ lens and images captured. Lutein cells were identified according to their distinct morphological appearance having a large round nucleus and abundant cytoplasm. A stratified procedure was used to ensure that cells examined were randomly chosen from all parts of the corpus luteum. Only cells that contained a visible nucleus were selected for analysis. Ten cells in each of the ten fields of view, which lay subjacent to the arms of a cross superimposed randomly on each field, were outlined and the area of each measured. The mean of these measurements was taken as representative of luteal cell area for that animal.

Changes in lutein cell area, as a result of the treatment, influences the proportion of the endothelial cells per unit area of tissue (Wulff et al. 2001a). Thus, with treatment causing a reduction in the size of the luteal cells, blood vessels would move closer together and the number of endothelial cells in a given area would be overestimated. To adjust for this, a conversion factor based on lutein cell area was used to correct the quantification of CD31 staining. The mean cell area for each group was determined and the conversion factor for each group was expressed as a ratio to the mean lutein cell area for the group with the largest cell area, i.e. the day 2 control group (Table 1). Relative endothelial cell area (i.e. CD31positive cells) was determined by thresholding the CD31-positive stained area and calculating the same as a percentage of total luteal area. The mean area of staining was then multiplied by the conversion factor, thus enabling the effect of VEGF inhibition on vascular density to be determined independently of the effects of treatment in suppressing lutein cell size.

Cellular proliferation was measured by counting both the number of BrdU-positive nuclei and the total number of nuclei in the selected fields. A proliferation index (i.e. BrdU-positive nuclei expressed as a percentage of the total number of nuclei) was calculated for each corpus luteum. In the mid-luteal phase, co-localisation analysis showed that $84 \%$ of proliferating cells are endothelial (Dickson \& Fraser 2000).
Table 1 Mean area of hormone-producing cells in corpora lutea of controls and in marmosets after treatment with VEGF Trap for 1, 2 and 4 days.

\begin{tabular}{lcc}
\hline Treatment & Mean cell area $\left(\mu \mathrm{m}^{2}\right)$ & Conversion factor* \\
\hline Controls & & \\
Day 2 & $674 \pm 41^{\mathrm{a}}$ & 1.0 \\
Day 4 & $579 \pm 30^{\mathrm{a}}$ & 0.86 \\
VEGF Trap & & 0.67 \\
Day 1 & $450 \pm 74^{\mathrm{a}}$ & 0.53 \\
Day 2 & $355 \pm 70^{\mathrm{b}}$ & 0.48 \\
Day 4 & $325 \pm 31^{\mathrm{b}}$ & \\
\hline
\end{tabular}

*Changes in lutein cell area as a result of treatment influence the proportion of other cells (e.g. endothelial cells) per unit area of tissue. To adjust for the effect of decrease in lutein cell size associated with the treatment, a conversion factor was calculated by dividing all values by the mean value of the largest group, i.e. control day 2. To compensate for the decrease in luteal cell area with treatment, the area of CD31 staining at each time point was multiplied by the conversion factor for that group. Different letters denote significant differences from respective control.

To determine the extent of cell death in sections stained with activated caspase-3, the number of activated caspase-3-positive cells in a given field was expressed as a percentage of the total number of cells in that area.

In sections dual-stained for caspase- 3 and CD31, all caspase-3-positive cells in each corpus luteum were counted and classified as being either dual-stained for CD31 (endothelial origin) or unstained for CD31 but of a size similar to that of hormone-producing cells. In addition, a minority of stained structures could not be classified with confidence under either category; these represented $<10 \%$ of the total in each group and did not influence the result. For each animal, the proportion of caspase-3-positive cells that were vascular endothelium or hormone-producing cells was determined by dividing the number by the total number of cells stained for caspase-3.

\section{Statistical analysis}

The significance of differences between means were determined by ANOVA followed by Bonferroni's posttest with $P<0.05$ being considered significant. The changes in the number of endothelial cells and hormone-producing cells over time were converted to a percentage and differences analysed using a $\chi^{2}$ followed by Fisher's exact test.

\section{Results}

\section{Effects of VEGF Trap on progesterone levels and the ovarian cycle}

Control marmosets, given Fc at the late luteal phase, exhibited a gradual decline in plasma progesterone concentrations typical of the latter stages of a normal luteal phase (Fig. 1). In contrast, VEGF Trap treatment at 

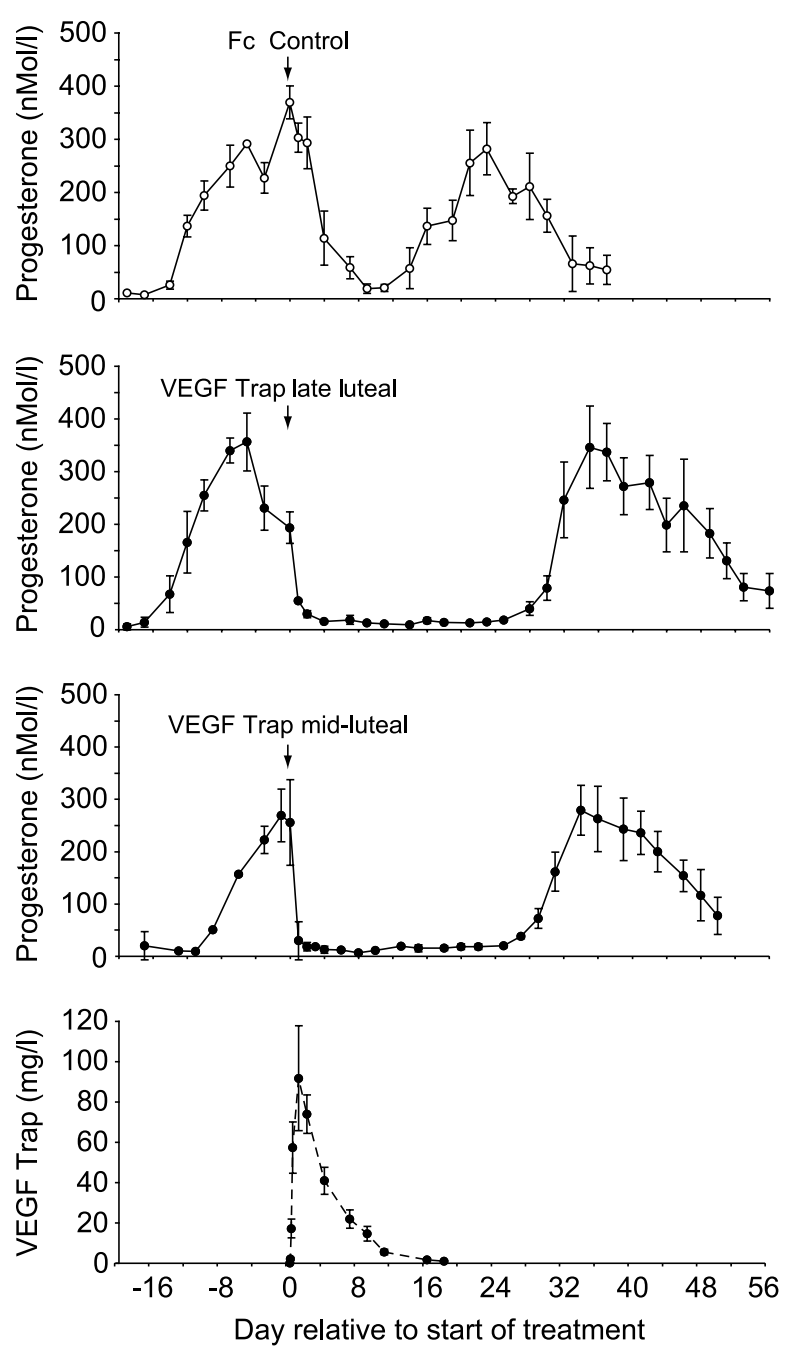

Figure 1 Effect of $F_{C}(25 \mathrm{mg} / \mathrm{kg}$ s.c.) at the late luteal phase $(O)$ or VEGF Trap (25 mg/kg s.c.) ( ) at the late or mid-luteal phase on plasma progesterone concentrations in the marmoset. Data are centred around the start of treatment (arrow). Note that progesterone secretion continues for a further 7 days and subsequent ovulation occurs approximately 8 days after luteolysis in the control group. Following VEGF Trap ( $25 \mathrm{mg} / \mathrm{kg}$ s.c.) administration at the mid- or the late luteal phase, functional luteal regression takes place within 2 days, while post-treatment ovulation, as determined by post-treatment rise of progesterone, is delayed until 28 days. Data are mean \pm s.E.M. $(n=5$ per group). The bottom panel shows pharmacokinetics of VEGF Trap in plasma. Values are mean \pm S.E.M.

the mid- or the late luteal phase was followed by a precipitous, premature decline in plasma progesterone concentrations that was significantly different $(P<0.001)$ from pre-treatment values by 1 day after treatment (Fig. 1). It is noted that, in the late luteal group receiving VEGF Trap, the progesterone concentrations appeared to be declining at the onset of treatment. However, values were still in the region of $200 \mathrm{nmol} / \mathrm{l}$ at the time and the resulting precipitous fall in progesterone during the first day would not be observed during the normal 20-day luteal phase. No recovery of progesterone was evident in the treated animals during the remainder of the luteal phase. With respect to recovery of post-treatment cycles, control marmosets ovulated about 16 days after receiving Fc (10 days after spontaneous luteolysis; Fig. 1). In contrast, progesterone levels remained suppressed for approximately 28 days in animals that received VEGF Trap, at which time a sustained rise in progesterone, indicative of ovulation and restoration of normal luteal function was seen (Fig. 1). Thus, a single injection of $25 \mathrm{mg} / \mathrm{kg}$ VEGF Trap resulted in functional luteolysis and extended the subsequent follicular phase by approximately 18 days.

Measurement of VEGF Trap in plasma showed that the time to reach maximal concentration of free VEGF Trap, $100 \pm 25 \mathrm{mg} / \mathrm{l}$, was $31 \pm 5 \mathrm{~h}$. The elimination half-life $(t 1 / 2)$ was $59 \pm 3$ h. By day 16 post-treatment, VEGF Trap levels had declined to $1 \mathrm{mg} / \mathrm{l}$ or less, at which time follicular growth was re-initiated as indicated by the occurrence of ovulation 10-12 days thereafter (Fig. 1).

In the second study where ovaries were collected posttreatment for analysis, plasma progesterone remained elevated at all time points, up to 2, 4 and 8 days, evaluated in control animals (Fig. 2). In contrast, significant decreases in progesterone $(P<0.01)$ were observed by 1 day after treatment in all VEGF Traptreated groups compared with their respective controls and levels remained significantly suppressed for the duration of the study period (Fig. 2).

\section{Morphology of corpora lutea}

Ovarian weight was significantly lowered $(P<0.01)$ by 4 days post-treatment (Fig. 3). Examination of ovaries stained with haematoxylin and eosin showed that corpora lutea of the current cycle were readily identifiable by their predominant size; luteal tissue originating from the previous cycle was markedly regressed and contained atrophied cells and fibroblasts. The number of corpora lutea of the present cycle in the individual marmosets (mean \pm s.E.M.) were as follows: controls, $2.75 \pm 0.25,3.0 \pm 0.41$ and $3.0 \pm 0.37$ for days 2,4 and 8 respectively and for treated animals, $2.25 \pm$ $0.25,3.0 \pm 0.41,2.25 \pm 0.25$ and $2.83 \pm 0.4$ for days 1 , 2,4 and 8 respectively. There was no significant difference between these groups. The measurement of luteal area revealed that the mean size of corpora lutea remained unchanged over the 8-day study period in the control group, while the corpora lutea in ovaries from the VEGF Trap-treated animals were significantly reduced in size by 2 days post-treatment $(P<0.005)$, with significant reductions being evident at $4(P<0.005)$ and 8 days $(P<0.002)$ post-treatment (Fig. 3$)$. In addition, the area of individual hormone-producing cells was decreased following administration of VEGF Trap. A significant decrease in lutein cell area $(P<0.01)$ was evident by days 2 and 4 (Table 1). Luteal cell area was not analysed at 8 days post-treatment because of the extensive 

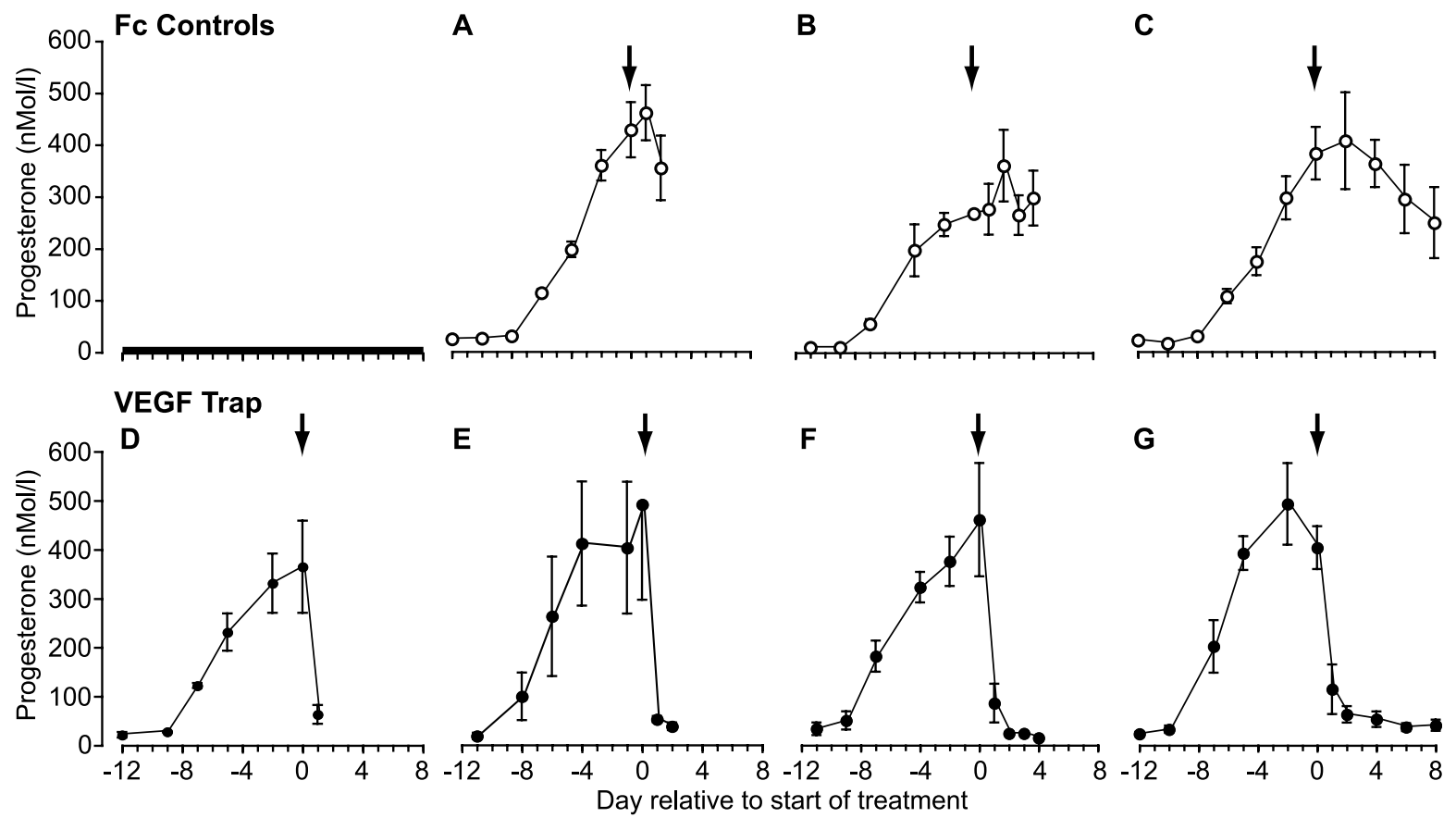

Figure 2 Plasma progesterone concentrations in the marmoset after injection at the mid luteal phase of control Fc (O) for (a) 2 , (b) 4 or (c) 8 days, and after VEGF Trap (O) for (d) 1, (e) 2, (f) 4 or (g) 8 days. Data are centred around the start of treatment (arrow). Note that progesterone continues at luteal phase levels after Fc, while after VEGF Trap functional luteal regression takes place. Treatment caused a significant suppression $(P<0.01)$ by one day in all groups. Values are mean \pm s.E.M. ( $n=4$ per group, or $n=6$ for 8 -day groups).

degenerative changes evident at this time in some of the corpora lutea recovered from animals that received VEGF Trap.

Haematoxylin and eosin staining showed healthy corpora lutea devoid of apoptotic cells or bodies in all control animals (Fig. 4a). After 1, 2 and 4 days after treatment with VEGF Trap, condensed bodies, albeit scarce, were observed amongst otherwise healthy cells (Fig. 4b-d). By 8 days post-treatment, corpora lutea of three VEGF Trap-treated animals contained predominantly intact hormone producing cells (Fig. 4e), while in two animals corpora lutea were markedly degenerated, exhibiting hormone-producing cells with large areas of vacuolation or condensed cells (Fig. 4f). In the remaining treated animal, the corpora lutea comprised a mixture of intact and degenerating regions.

Sections stained for the activated caspase-3 were evaluated to identify and quantify dying cells. Caspase3 -positive cells were either absent or very rare in corpora lutea of control animals (Fig. 5a), while in the granulosa cells of atretic follicles in these same ovaries, staining was intense, confirming efficacy of the identification procedure. After 1, 2 or 4 days of VEGF Trap treatment, staining for activated caspase-3 was evident throughout the corpora lutea (Fig. 5b-g). At 1 and 2 days posttreatment, the caspase-3-positive cells were small and had the shape of endothelial cells (Fig. 5b), or clearly followed the course of a blood vessel (Fig. 5c), strongly suggesting that they were of endothelial origin. In some instances, some microcapillaries appeared to be occluded by caspase-3-positive cells (Fig. 5d). Endothelial cells lining the large blood vessels in the corpus luteum appeared healthy, apart from the occasional positive cells that were clearly of endothelial origin (Fig. 5e). Cells staining positively for activated caspase-3 were sometimes found within these vessels and may
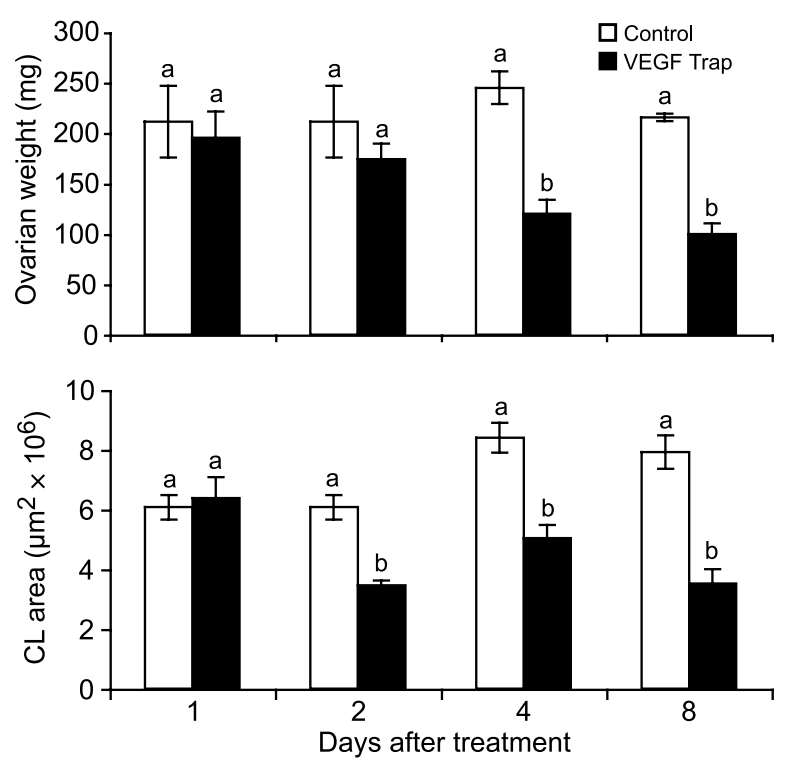

Figure 3 Effect of injection of Fc or VEGF Trap administered at the mid-luteal phase on ovarian weight and corpus luteum area after 1, 2, 4 or 8 days in the marmoset. Significant differences indicated by different letters. Values are mean \pm s.E.M. 

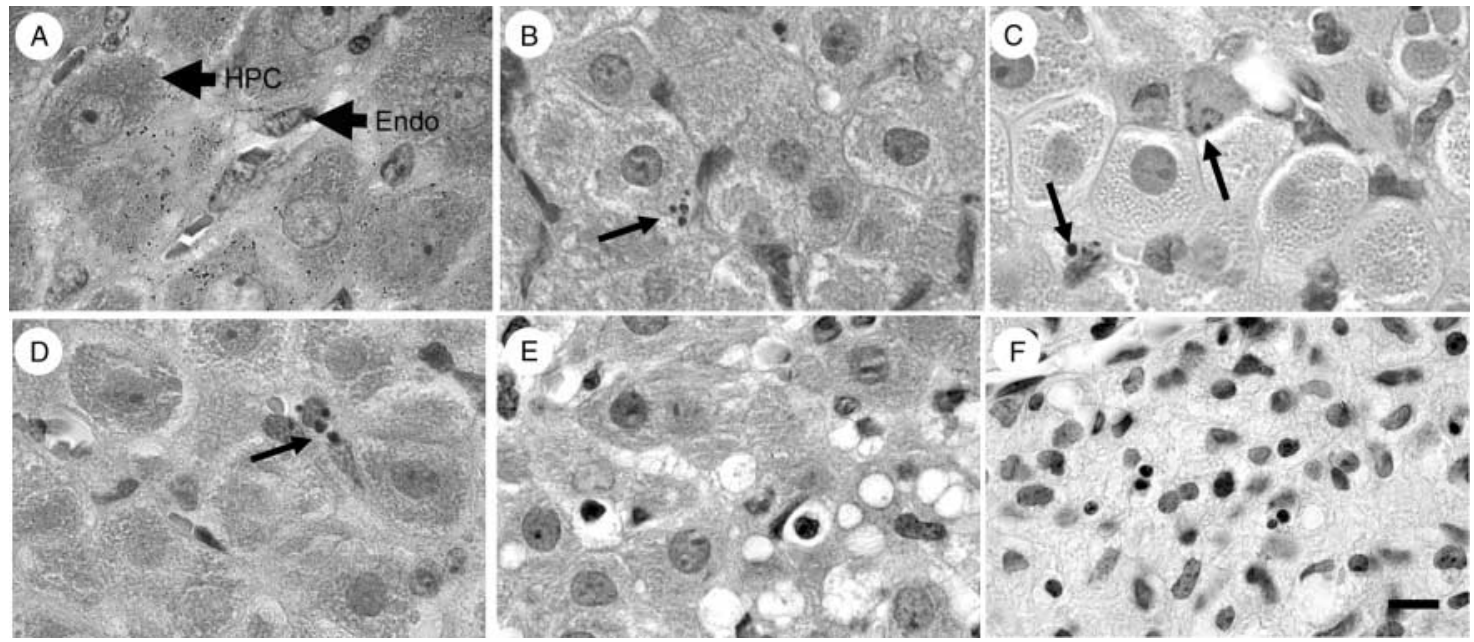

Figure 4 Effect of Fc (control) or VEGF Trap treatment at the mid-luteal phase on appearance of luteal cells after 1, 2, 4 or 8 days. Photomicrograph showing corpora lutea stained with haematoxylin and eosin in (a) control marmoset, 2 days post-Fc, (b) after treatment with VEGF Trap for 1 , (c) 2, (d) 4 or (e) and (f) 8 days. Note the intact hormone-producing cells and endothelial cells (Endo), thick arrows, in the control. Note the apoptotic cells (thin arrows) surrounded by healthy hormone-producing cells after VEGF Trap in (b)-(d). Note after 8 days treatment the corpora lutea contained a mixture of apparently healthy or dying cells (e) or were markedly regressed (f). Bar $=10 \mu \mathrm{m}$.

represent detached endothelium (Fig. 5f). By day 2, while staining in some corpora lutea was largely confined to the vascular compartment in others, larger cells that had the appearance of hormone-producing cells began to be stained and by day 4 , stained cells were predominantly large, presumptive lutein cells (Fig. 5g). After 8 days, the number of caspase-3-stained cells was relatively scarce and confined to the larger, hormoneproducing cells (Fig. 5h), or absent in cases of more advanced luteal degeneration. Quantitative analysis showed that the total number of cells stained for activated caspase- 3 was significantly higher $(P<0.001)$ in VEGF Trap-treated marmosets than in control animals at 1,2 , or 4 days post-treatment (Fig. 5i).

Dual staining with activated caspase- 3 and CD31 provided definitive identification of dying endothelial cells. One day following VEGF Trap administration, activated caspase-3 staining (brown stain) was evident predominantly in cells that also were positive for CD31 (blue stain; Fig. 6a). After 2 days, staining was more evenly distributed between CD31-positive and -negative cell types (Fig. 6b), while at 4 days post-treatment, the majority of brown-stained cells were large and unstained for CD31, indicating that they were hormone-producing cells (Fig. 6c). The preferential death of endothelial cells at 1 day post-treatment was confirmed after counting the percentage of cells dual stained for CD31 and caspase-3 at various time points (Fig. 6d). Endothelial cell death was significantly higher $(P<0.001)$ than that of the hormone-producing cells on day 1 . Thereafter, the percentage of positive endothelial cells declined while that of hormone-producing cells increased, so that the ratio between the two was significantly different $(P<0.001)$ on each of the days 1,2 and 4 .
Cell proliferation, as evidenced by BrdU incorporation, was detected in all control corpora lutea, albeit at much lower levels than in the early luteal phase (Fig. 7). Administration of VEGF Trap produced a significant $(P<0.05)$ reduction in BrdU incorporation 1 and 2 days post-treatment relative to the control group, but not at later time points, as proliferation levels continued to decline in controls in the second half of the luteal phase, days 4 and 8 post-treatment control being significantly less $(P<0.05)$ than the day 2 control value.

The appearance of the corpora lutea after CD31 staining to localise the blood vessels after days 1, 2 and 4 treatment is shown in Fig. 8a-d. Quantitative analysis revealed a degree of individual variation such that the relative area of CD31 staining in the corpora lutea of VEGF Trap-treated marmosets relative to their respective controls was not statistically different (Fig. 8e). However, when the conversion factor was used to adjust for the decrease in luteal cell cross-sectional area evident in the treated groups, the decline in CD31 staining became significant $(P<0.05)$ at 1 and 2 days post-treatment (Fig. 8f). By day 8, CD31 staining was inconsistent in the corpora lutea of many animals in the VEGF Trap-treated group (data not shown) and therefore not subjected to quantitative analysis.

\section{Discussion}

These results show that VEGF Trap administered during the mid- or the late luteal phase, when angiogenesis is largely complete in the marmoset and other primates (Gaytan et al. 1998, Dickson \& Fraser 2000, Wulff et al. $2001 a, b)$, has an unexpected effect of inducing a rapid functional luteolysis in the marmoset monkey. This 

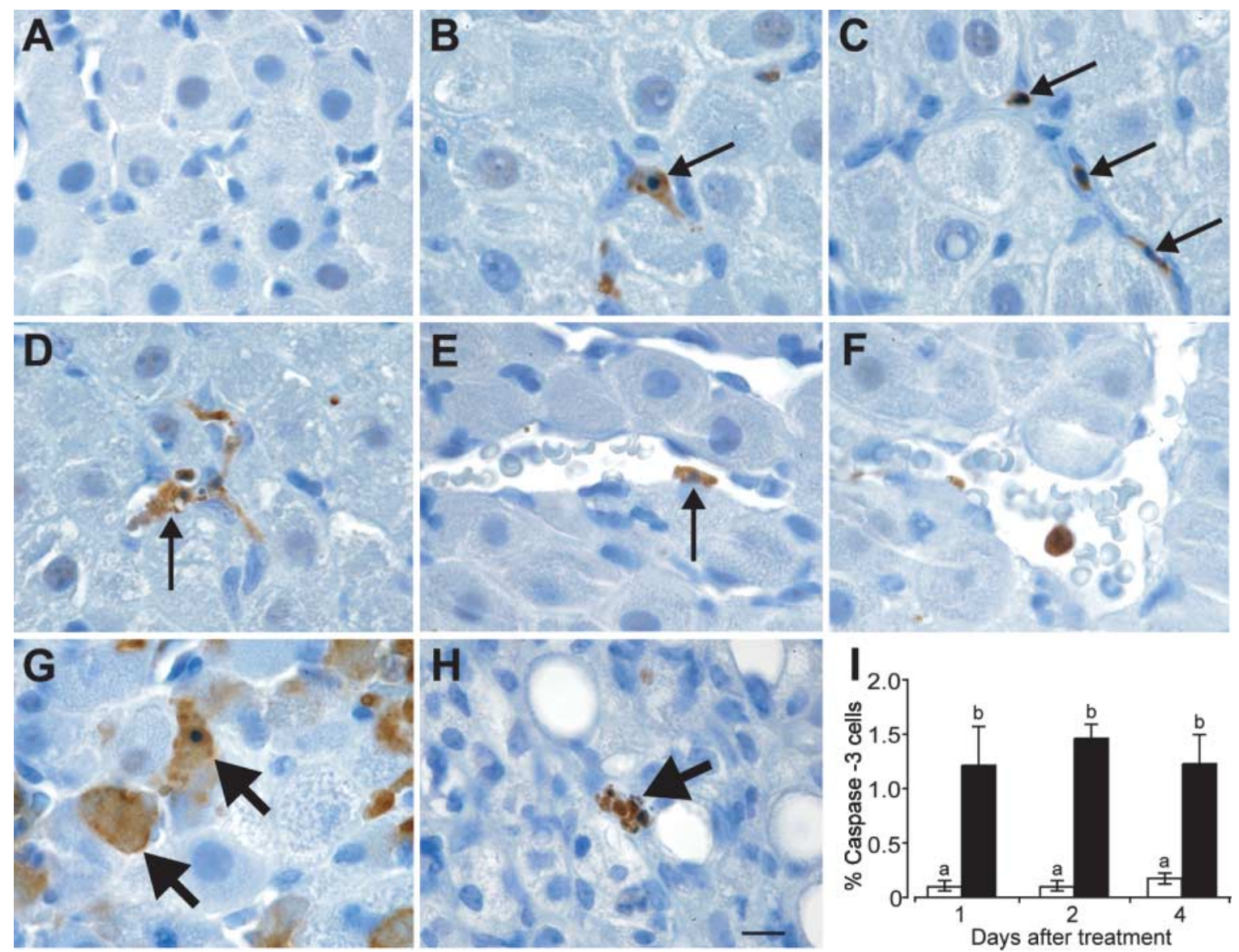

Figure 5 Corpora lutea stained for activated caspase-3 (brown) in sections counter-stained with haematoxylin (blue). Note the absence of staining in the mid-luteal control (a), while after 1 or 2 days following VEGF Trap treatment staining of presumptive endothelial cells (thin arrows) is evident (b)-(f). The pattern of staining was predominantly of individual endothelial cells (b) while, on occasion, a number of cells along the track of a blood vessel also containing non-stained cells was evident (c). Accumulation of positive cells in a blood vessel was also sometimes found (d). Large blood vessels in the corpus luteum were largely negative for caspase-3 although positive cells were sometimes found (e). In (f), a large blood vessel with a detached positive presumptive endothelial cell is shown. After 4 days of treatment, predominantly large cells, hormone-producing cells are (thick arrows) stained (g). Eight days after VEGF Trap staining was absent or present in a few large cells (h). Histogram shows quantification of percentage cells staining for activated caspase-3 in control corpora lutea and in corpora lutea from marmosets after 1, 2 or 4 days after VEGF Trap (i). Values are mean \pm s.E.M. Significant difference from control group denoted by letter a. Bar $=10 \mu \mathrm{m}$.

strongly suggests that VEGF Trap treatment affects luteal function by mechanisms other than inhibition of angiogenesis. One mechanism involved is the premature and selective death of endothelial cells, as determined by dual staining for activated caspase- 3 and CD31. This was a short-lived phenomenon, being most evident 1 and 2 days following treatment, followed by a progressive increase in the death of lutein cells and a decrease in corpus luteum area and ovarian weight. This is the first demonstration that endothelial cell death can be triggered selectively in the primate corpus luteum, coincident with functional luteolysis and prior to the initiation of death in the hormone-producing cells. The findings are likely to be relevant to higher primates since VEGF administration to macaques at the mid-luteal phase also resulted in the suppression of progesterone secretion (Fraser et al. 2005a).
The corpus luteum is unusual in that it is a tissue that undergoes natural regression, which is associated with resorption of the vasculature (Modlich et al. 1996, Augustin 2000). This raises the question as to whether the changes observed following VEGF Trap administration are similar to those occurring during natural luteolysis. Involvement of endothelial cell death in the initial stages of luteal regression has been described in guinea pigs (Azmi \& O'Shea 1984) and sheep (Sawyer et al. 1990) with occlusion of blood vessels by cellular debris, presumably detached endothelial cells. Based on this, it has been proposed that spontaneous luteolysis might be initiated by endothelial loss, which then triggers a cascade of events: occlusion of local microvessels leading to ischemia and further apoptosis of endothelial cells accompanied by apoptosis of hormone-producing cells (Azmi \& O'Shea 1984, Sawyer et al. 1990). While 


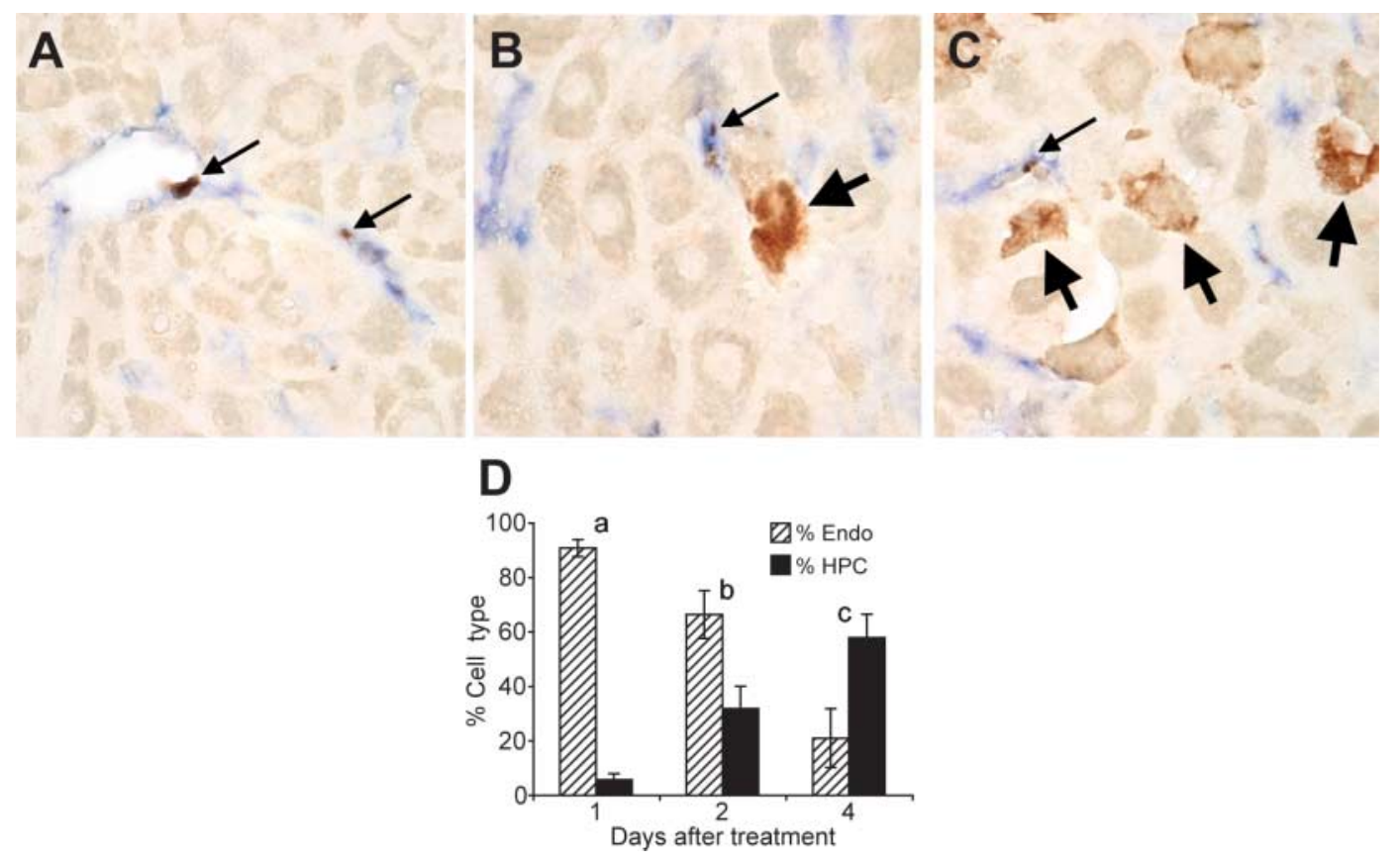

Figure 6 Photomicrograph showing corpora lutea from animals treated with VEGF Trap dual stained with activated caspase-3 (brown) and CD31 (blue) to identify endothelial cells. Note in VEGF Trap treatment for 1 or 2 days results in (a) staining of endothelium (thin arrows) or (b) both hormone-producing cells (thick arrows) and endothelium, while after 4 days, (c) staining is predominantly in hormone-producing cells. (d) Histogram comparing percentage of endothelial dual-stained with activated caspase- 3 and hormone-producing cells stained with activated caspase3 after 1, 2 or 4 days following VEGF Trap. Results show significant changes in ratio of cell types with time (different letters), notably the preponderance endothelial cells stained with caspase- 3 after 1 day of treatment followed by an increasing percentage of hormone-producing cells on days 2 and 4 . Values are mean \pm S.E.M. Bar $=10 \mu \mathrm{m}$.

this sequence of events is consistent with the effects of pharmacological VEGF inhibition in marmoset, as described in the present study, there is no clear evidence that spontaneous luteal regression in primates is initiated at the level of the vascular endothelium. For example, in marmosets, spontaneous functional luteolysis clearly precedes structural dissolution. The onset of cell death in the regressing corpus luteum, as determined by haematoxylin and eosin staining or in situ 3 '-end labelling, is not observed until functional luteolysis is well underway, such that luteal cell death is not maximal until the early follicular phase of the succeeding cycle (Young et al. 1997). In addition, death of hormone-producing and endothelial cells was consistently observed to occur contemporaneously. Similarly, in humans, the peak level of cell death in the corpus luteum is apparent during the peri-menstrual period, with no evidence of this being preceded by preferential endothelial cell loss (Gaytan et al. 1998, Morales et al. 2000), while in the regressing equine corpus luteum, we have found that activated caspase-3 staining appears simultaneously in the hormone-producing and the endothelial cells (Aguilar et al. 2006). These and other observations (Funayama et al. 1996) indicate that structural luteolysis normally follows functional luteolysis in the primate, and there is as yet no convincing evidence to show that during this process, endothelial cells die before hormone-producing cells.
It is also relevant to compare the effects of VEGF inhibition to those observed after induction of luteolysis, after administration of either a gonadotrophin-releasing hormone antagonist or a prostaglandin $F_{2 \alpha}$ analogue during the mid-luteal phase in the marmoset. These treatments also resulted in a marked decrease in plasma progesterone within $24 \mathrm{~h}$, but in addition were associated with massive structural degeneration especially in the

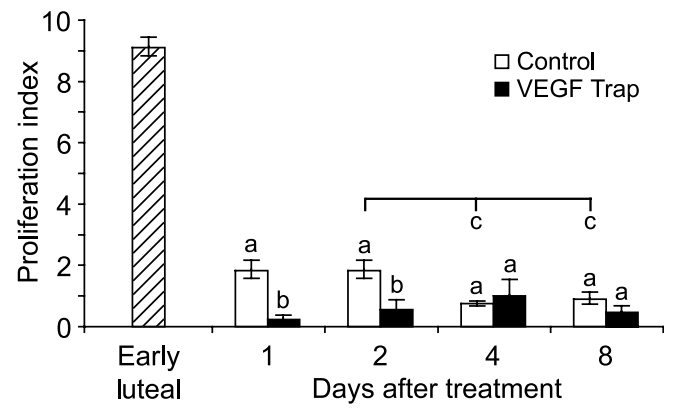

Figure 7 Effect of Fc (control) or VEGF Trap given at the mid-luteal phase on the number of BrdU-labelled cells in the corpora lutea after 1 , 2, 4 or 8 days. The shaded bar shows proliferation index at the early luteal phase derived from a previous study to show the comparative 'post-angiogenic' state at the beginning of the current study. Different letters $(a, b)$ denote significant differences between each control and treated group. Bar and different letters $(\mathrm{a}, \mathrm{c})$ indicate significant shows differences between day 2 control group and the 4 and 8 day controls. Values are mean \pm s.E.M. 

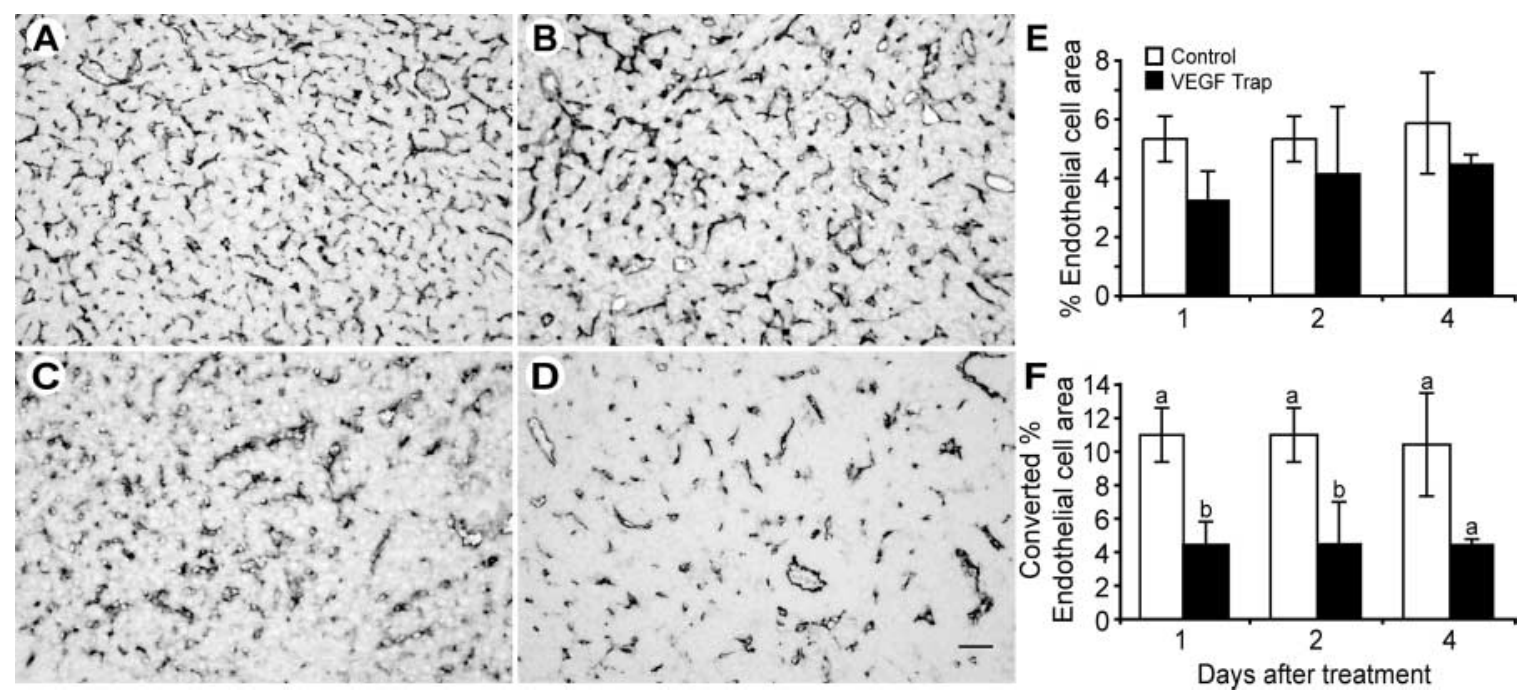

Figure 8 Low power photomicrograph of CD31 staining to show the vasculature in corpora lutea of (a) control and (b) 1, (c) 2 and (d) 4 days following VEGF Trap, (e) area of staining in the controls and in animals treated up to 4 days. The same data ( $\mathrm{f}$ ) after the conversion factor has been applied to take into account the reduction in area of the hormone-producing cells after treatment revealing a significant reduction in endothelial cell area (different letters) at 1 and 2 days post-treatment. Values are mean \pm s.E.M. Bar $=50 \mu \mathrm{m}$.

hormone-producing cells within that time frame (Young et al. 1997, Fraser et al. 1999). The changes observed 1,2 and 4 days after VEGF Trap were less extensive, and haematoxylin and eosin staining showed that they did not exhibit the vacuolation of hormone-producing cells associated with these treatments (Fraser et al. 1999). We know that 5 days after prostaglandin analogue treatment, luteal tissue is clearly regressed, both functionally and structurally (Fraser HM, unpublished observations). However, even at 8 days following VEGF Trap, such degeneration was found only in one-half of the corpora lutea, the remainder retaining a component of relatively healthy hormone-producing cells.

In a previous study, administration of a VEGFneutralising antibody during the mid-luteal phase in the marmoset produced a partial and transient decline in plasma progesterone secretion, which recovered after a few days (Dickson et al. 2001) in contrast to the more profound and continued functional luteolysis observed after VEGF Trap. In that study, a low level of apoptosis of endothelium was also reported, but this was not followed by a structural luteolysis of hormone-producing cells. However, these findings do support the claim that VEGF inhibition initiates a distinctive sequence of changes in the mature marmoset corpus luteum by selectively precipitating the death of a subset of vascular of endothelial cells. Examination of the consequences of VEGF inhibition in other experimental systems has similarly provided evidence for preferential induction of endothelial cell death. For example, VEGF inhibition causes the rapid dissolution of a subset of tumour blood vessels, associated with the preferential loss of endothelial cells rather than associated pericytes or tumour cells (Benjamin et al. 1999). In the present study, endothelial cell apoptosis declined after 2 days and significant numbers of CD31-positive cells persisted at and beyond this time point, suggesting that it is a subset of endothelial cells in the established luteal vasculature that is also differentially susceptible to the initial effects of VEGF withdrawal.

In the present study, VEGF inhibition further suppressed endothelial cell proliferation evident at the midluteal phase. However, suppression of the already low level of angiogenesis at this stage is unlikely to be a significant factor mediating the observed rapid decline in progesterone levels produced by VEGF Trap, as this was also seen when treatment was initiated at the late luteal phase, at the time of very low endothelial cell proliferation in control animals and not subject to further reduction by VEGF inhibition.

Although induction of endothelial cell death, rather than inhibition of angiogenesis per se, is likely to be an important factor in triggering the luteolysis observed following the administration of VEGF Trap, downstream changes and alterations in the structure or function of surviving endothelial cells might well contribute substantially to the loss of luteal function. Since the fall in plasma progesterone is rapid, profound and precedes the death of hormone-producing cells, more subtle changes in the regulation of the tissue will need to be examined by further study. For example, VEGF is known to promote vascular permeability and the pharmacological inhibition of VEGF effectively suppresses vascular leak and oedema in numerous pathological and experimental conditions (Bates \& Harper 2003, Inai et al. 2004). Moreover, VEGF inhibition rapidly induces the loss of endothelial fenestrations in pancreatic tumours, thyroid glands and renal glomerular capillaries of mice, and can 
also reduce blood flow in physically intact tumour vessels (Inai et al. 2004, Kamba et al. 2006). VEGF Trap has also been shown to decrease permeability in a tumour model (Byrne et al. 2003). Thus, it is likely that reductions in blood flow and/or vascular permeability may also play significant roles in the rapid fall in progesterone levels observed in the present studies, by depriving lutein cells of necessary nutrients or factors. Unfortunately, investigation of such changes is not readily assessable with the present techniques in these primates.

The principal way in which VEGF promotes luteal angiogenesis and function is that following its synthesis by the hormone-producing cells in the corpus luteum it acts via its receptors on endothelial cells (Wulff et al. $2001 \mathrm{~b}$ ). Thus, the primary site of action of the Trap is to bind to the VEGF released by the hormone-producing cells and prevent it from reaching its receptor. With the development of degenerative changes to hormoneproducing cells, a secondary effect of decreased release of VEGF would be expected. Additional mechanisms follow from reports of localisation of VEGF receptors on luteal cells of the human corpus luteum (Sugino et al. 2000) and in vitro studies on bovine granulosa and thecal cells that provided evidence that VEGF from hormone-producing cells may also act in an autocrine or paracrine manner to protect against cell death (Greenaway et al. 2004). Although, there is no evidence, as yet, for such a system operating in the marmoset corpus luteum, if it were demonstrated, then effects of VEGF Trap treatment could be attributed to direct inhibitory actions on both the endothelium and hormone-producing cells.

Despite the luteal endothelial cell apoptosis, luteal blood vessels were still present even after 8 days exposure. Comparison with experiments in which VEGF has been inhibited in the mouse, indicate that the vasculature of the marmoset is more resistant to VEGF deprivation. Using the approach of immunoneutralisation of the VEGF receptor-2 in pregnant mice, Pauli et al. (2005) have shown that luteal structural regression and disappearance of the vasculature results even though apoptosis of hormone-producing cells rather than endothelial cells was observed. This may suggest that luteal endothelial cells are more susceptible in the mouse, or there are differences in response when the VEGF receptor-2 is blocked specifically, as opposed to the deprivation of VEGF stimulation to all its receptors by VEGF Trap.

When the concept of anti-angiogenesis treatment of solid tumours was proposed, it was assumed that the only vasculature susceptible in healthy tissue of the adult would be that occurring in the female reproductive tract (Folkman 1992, Ferrara 2004). However, the fact that many tissues express VEGF suggests it may have a 'housekeeping' role. Indeed, the availability of VEGF antagonists for in vivo administration should allow the elucidation of its physiological role in these tissues. Studies in mice also show that VEGF antagonist treatment results in capillary regression in glands expressing VEGF, the pancreatic islets, thyroid, adrenal cortex and pituitary gland (Kamba et al. 2006). Capillaries in these tissues grew back after cessation of treatment. It is intriguing that regression of thyroid capillaries by $68 \%$ did not result in changes in plasma free thyroxin levels (Kamba et al. 2006). This contrasts with the marked decline in plasma progesterone in the present study, which was associated with a more modest decline in the luteal vasculature. While it is reassuring that there were no apparent effects of the VEGF Trap on the health of the marmosets, the fact that all relevant tissues have been collected from the animals involved in terminal experiments should allow possible effects in addition to the reproductive system to be investigated.

In conclusion, inhibition of VEGF during the midluteal phase in the marmoset results in a rapid and sustained functional luteolysis. Since a functioning corpus luteum is required for the establishment of pregnancy, alterations in endogenous VEGF at this time could affect fertility. The phenomenon is associated with an early and specific loss of a subset of luteal endothelial cells, but other early changes, such as effects on ovarian vascular permeability should be addressed by further investigation.

\section{Acknowledgements}

We thank Keith Morris and staff for animal care, Ian Swanston for VEGF Trap and progesterone assays, and Ted Pinner and Corinne Macleod for graphics.

\section{References}

Aguilar J, Fraser HM, Wilson H, Clutton E, Shaw DJ \& Watson ED 2006 Temporal relationship between proliferating and apoptotic hormone-producing and endothelial cells in the equine corpus luteum. Reproduction 132 111-118.

Augustin HG 2000 Development of the vascular system of the corpus luteum. In Morphogenesis of Endothelium, pp 237-254. Ed. W Risau. Reading, UK: Harwood Academic Publishers.

Azmi TI \& O'Shea JD 1984 Mechanism of deletion of endothelial cells during regression of the corpus luteum. Laboratory Investigation $\mathbf{5 1}$ 206-217.

Bates DO \& Harper SJ 2003 Regulation of vascular permeability by vascular endothelial growth factors. Vascular Pharmacology 39 225-237.

Benjamin LE, Golojanin D, Itin A, Pode D \& Keshet E 1999 Selective ablation of immature blood vessels in established human tumors follows vascular endothelial growth factor withdrawal. Journal of Clinical Investigation 103 159-165.

Byrne AT, Ross L, Holash J, Nakanishi M, Hu L, Hofmann JI, Yancopoulos GD \& Jaffe RB 2003 Vascular endothelial growth factor-trap decreases tumor burden, inhibits ascites, and causes dramatic vascular remodelling in an ovarian cancer model. Clinical Cancer Research 9 5721-5728. 
Carambula SF, Matikainen T, Lynch MP, Flavell RA, Goncalves PB, Tilly JL \& Rueda BR 2002 Caspase-3 is a pivotal mediator of apoptosis during regression of the ovarian corpus luteum. Endocrinology 143 1495-1501.

Dickson SE \& Fraser HM 2000 Inhibition of early angiogenesis by gonadotropin releasing hormone antagonist treatment in the primate. Journal of Clinical Endocrinology and Metabolism 85 2339-2344.

Dickson SE, Bicknell R \& Fraser HM 2001 Mid-luteal angiogenesis and function in the primate is dependent on vascular endothelial growth factor. Journal of Endocrinology 168 409-416.

Ferrara N 2004 Vascular endothelial growth factor: basic science and clinical progress. Endocrine Reviews 25 581-611.

Folkman J 1992 Angiogenesis in female reproductive organs. In Steroid Hormones and Uterine Bleeding, pp 143-158. Eds NJ Alexander \& C D'Arcangues. Washington, DC: AAAS Press.

Fraser HM \& Duncan WC 2005 Vascular morphogenesis in the primate ovary. Angiogenesis 8 101-116.

Fraser HM, Lunn SF, Harrison DJ \& Kerr JB 1999 Luteal regression in the primate: different forms of cell death during natural and gonadotropinreleasing hormone antagonist or prostaglandin analogue-induced luteolysis. Biology of Reproduction 61 1468-1479.

Fraser HM, Dickson SE, Lunn SF, Wulff C, Morris KD, Carroll V \& Bicknell R 2000 Suppression of luteal angiogenesis in the primate after neutralization of vascular endothelial growth factor. Endocrinology 141 995-1000.

Fraser HM, Wilson H, Rudge JS \& Wiegand SJ 2005a Vascular endothelial growth factor trap suppresses ovarian function at all stages of the luteal phase in the macaque. Journal of Clinical Endocrinology and Metabolism 90 5811-5818.

Fraser HM, Wilson H, Rudge JS \& Wiegand SJ 2005b Single injections of vascular endothelial growth factor trap block ovulation in the macaque and produce a prolonged, dose-related suppression of ovarian function. Journal of Clinical Endocrinology and Metabolism $901114-1122$.

Funayama Y, Sasano H, Suzuki T, Tamura M, Fukaya T \& Yajima A 1996 Cell turnover in normal cycling human ovary. Journal of Clinical Endocrinology and Metabolism 81 828-834.

Gaytan F, Morales C, Garcia-Pardo L, Reymundo C, Bellido C \& Sanchez-Criado J 1998 Macrophages, cell proliferation, and cell death in the human menstrual corpus luteum. Biology of Reproduction 59 417-425.

Gilchrist RB, Wicherek M, Heistermann M, Naydu PL \& Hodges JK 2001 Changes in follicle stimulating hormone and follicle populations during the ovarian cycle of the common marmoset. Biology of Reproduction 64 127-135.

Greenaway JB, Connor K, Pedersen HG, Coomer BL, LaMarre J \& Petrik J 2004 Vascular endothelial growth factor and its receptor, Flk-1/KDR are cytoprotective in the extravascular compartment of the ovarian follicle. Endocrinology 145 2896-2905.

Harlow CR, Gems S, Hearn JP \& Hodges JK 1983 The relationship between plasma progesterone and the timing of ovulation and early embryonic development in the marmoset monkey (Callithrix jacchus). Journal of Zoology 201 273-282.

Harlow CR, Hearn JP \& Hodges JK 1984 Ovulation in the marmoset monkey: endocrinology, predication and detection. Journal of Endocrinology 103 17-24.

Holash J, Davis S, Papadopoulos N, Croll SD, Ho L, Russell M, Boland P, Leidich R, Hylton D, Burova E et al. 2002 VEGF-Trap: a VEGF blocker with potent antitumor effects. PNAS 99 11393-11398.

Inai $T$, Mancuso $M$, Hashizume $H$, Baffert F, Haskell A, Baluk P, HuLowe DD, Shalinsky DR, Thurston G, Yancopoulos GD et al. 2004
Inhibition of vascular endothelial growth factor (VEGF) signalling in cancer causes loss of endothelial fenestrations, regression of tumor vessels, and appearance of basement membrane ghosts. American Journal of Pathology 165 35-52.

Jabbour HN, Kelly RW, Fraser HM \& Critchley HOD 2006 Endocrine regulation of menstruation. Endocrine Reviews 27 17-46.

Jain RK, Duda DG, Clark JW \& Loeffler JS 2006 Lessons from phase III clinical trials on anti-VEGF therapy for cancer. Nature Clinical Practice. Oncology 3 24-40.

Kamba T, Tam BY, Hashizume H, Haskell A, Sennino B, Mancuso MR, Norberg SM, O'Brien SM, Davis RB, Gowen LC et al. 2006 VEGFdependent plasticity of fenestrated capillaries in the normal adult microvasculature. American Journal of Physiology. Heart and Circulatory Physiology $290 \mathrm{H} 560-\mathrm{H} 576$.

Modlich U, Kaup FJ \& Augustin HG 1996 Cyclic angiogenesis and blood vessel regression in the ovary: blood vessel regression during luteolysis involves endothelial cell detachment and vessel occlusion. Laboratory Investigation 74 771-780.

Morales C, Garcia-Pardo L, Reymundo C, Bellido C, Sanchez-Criado JE \& Gaytan F 2000 Different patterns of structural luteolysis in the human corpus luteum of menstruation. Human Reproduction 15 2119-2128.

Pauli SA, Tang H, Wang J, Bohlem P, Posser R, Hartman T, Sauer MV, Kitajewski J \& Zimmermann RC 2005 The vascular endothelial growth factor (VEGF)/NEGF receptor pathway is critical for blood vessel survival in corpora lutea of pregnancy in the rodent. Endocrinology 146 1301-1311.

Peluffo MC, Young KA \& Stouffer RL 2005 Dynamic expression of caspase-2, -3, -8, and -9 proteins and enzyme activity, but not messenger ribonucleic acid, in the monkey corpus luteum during the menstrual cycle. Journal of Clinical Endocrinology and Metabolism $902327-2335$.

Rowe AJ, Morris KD, Bicknell R \& Fraser HM 2002 Angiogenesis in the corpus luteum of early pregnancy in the marmoset and the effects of vascular endothelial growth factor immunoneutralization on establishment of pregnancy. Biology of Reproduction 67 1180-1188.

Sawyer HR, Niswender KD, Braden TD \& Niswender GD 1990 Nuclear changes in ovine luteal cells in response to PGF2 $\alpha$. Domestic Animal Endocrinology 72 229-238.

Sugino N, Kashida S, Takiguchi S, Karube A \& Kato H 2000 Expression of vascular endothelial growth factor and its receptors in the human corpus luteum during the menstrual cycle and in early pregnancy. Journal of Clinical Endocrinology and Metabolism 85 3919-3924.

Wulff C, Dickson SE, Duncan WC \& Fraser HM 2001a Angiogenesis in the human corpus lutem: simulated early pregnancy by HCG treatment is associated with both angiogenesis and vessel stabilisation. Human Reproduction 16 2515-2524.

Wulff C, Wilson H, Rudge JS, Wiegand SJ, Lunn SF \& Fraser HM 2001 b Luteal angiogenesis: prevention and intervention by treatment with vascular endothelial growth factor trap A40. Journal of Clinical Endocrinology and Metabolism 86 3377-3386.

Young FM, Illingworth PJ, Lunn SF, Harrison DJ \& Fraser HM 1997 Cell death during luteal regression in the marmoset monkey (Callithrix jacchus). Journal of Reproduction and Fertility 111 109-119.

Received 7 December 2005

First decision 1 February 2006

Revised manuscript received 8 May 2006

Accepted 26 June 2006 